\title{
Estabilidade e Transformação na Construção de Rotinas Compartilhadas no Grupo de Brinquedo
}

\section{Stability and Change in the Construction of Shared Routines in Playgroups}

\author{
Juliana Maria Ferreira de Lucena* \& Maria Isabel Pedrosa \\ Universidade Federal de Pernambuco, Recife, Pernambuco, Brasil
}

\begin{abstract}
Resumo
O trabalho investiga a construção de rotinas compartilhadas num grupo de brinquedo de crianças de dois anos. Apóia-se no referencial psicoetológico, que reconhece a espécie humana como biologicamente sociocultural, e a cultura como seu nicho ontogenético. A criança é concebida como agente de criação e transmissão de cultura. Dois episódios lúdicos são analisados. Eles evidenciam a construção de uma rotina em que se arrastam grandes objetos ao longo de um pátio coberto. Há momentos de estabilidade e transformação em seu desenrolar. As crianças reconhecem a estrutura de participação na rotina e lhe adicionam inovações. A produção coletiva parece orientar o grupo no desdobramento de suas atividades. Os dados são interpretados como evidências de processos culturais na primeira infância.

Palavras chave: Brincadeira, rotinas de interação social, cultura de grupo, processos de significação.

Abstract

This paper investigates the construction of shared routines in a playgroup of two-year-old children. It rests on a psychoethological approach, which recognizes the human being as a biologically socialcultural species, and culture as their ontogenetic niche. The child is conceived as an agent of creation and transmission of culture. Two ludic episodes are analyzed and they show the construction of a playful routine in which large objects are dragged along in a sheltered patio. There are moments of stability and transformation in the development of the task. Children recognize the structure of participation in the routine and add innovations to it. Collective production seems to guide the group in the development of the activities. The data are interpreted as evidence of cultural processes in early childhood.

Keywords: Play, social interaction routines, group culture, meaning-making process.
\end{abstract}

Este trabalho apóia-se em um referencial psicoetológico e dialoga com autores como Bruner (1983, 1990/2011), Hamann, Warneken, Greenberg e Tomasello (2011), Moll, Carpenter e Tomasello (2010), Tomasello (2003, 2009, 2011) e Wallon (1934/1971), que reconhecem a espécie humana como biologicamente sociocultural, e a cultura como nicho ontogenético dos seres humanos. Para esses autores, o modo como se efetivam as interações sociais humanas implica uma boa sintonização com o parceiro uma habilidade para negociar significados por intermédio da interpretação do outro e do que fazem juntos.

Tomasello (2003) argumenta que a capacidade particular do ser humano para "compreender os coespecíficos

\footnotetext{
* Endereço para correspondência: Centro de Filosofia e Ciências Humanas, Departamento de Psicologia, Universidade Federal de Pernambuco, $9^{\circ}$ andar, Av. da Arquitetura, s/n, Cidade Universitária, Recife, PE, Brasil 50740-550. E-mail:jmflucena@gmail.com e mariaisabel. pedrosa5@gmail.com

Agradecimentos: Financiamento Conselho Nacional de Desenvolvimento Científico e Tecnológico (CNPq) e Fundação de Amparo à Ciência e Tecnologia do Estado de Pernambuco (FACEPE).
}

como seres iguais a ele [itálico do autor], com vidas mentais e intencionais iguais às dele" (p. 7) é decisiva para que sejam capazes de aprender artefatos culturais por meios de interações com seus coespecíficos e transmitir essas informações para outras gerações de uma maneira específica ao modo humano de ser social. $\mathrm{O}$ argumento defendido é que não há nenhuma outra espécie com comportamentos que revelem uma evolução cultural cumulativa (efeito catraca), por meio da qual as tradições culturais acumulam modificações feitas por diferentes pessoas ao longo do tempo, de modo que elas se complexifiquem e incorporem inovações.

Essa especificidade parece ocorrer porque a evolução cultural cumulativa depende de dois processos - inovação e imitação. O primeiro está atrelado à capacidade de inventividade humana, e o segundo, à habilidade de sintonizar-se afetiva e cognitivamente ao coespecífico ao ponto de agir de maneira semelhante a ele, puramente por motivação social. Outros primatas, como os chimpanzés, são capazes de aprender com os seus coespecíficos por imitação. A aprendizagem, contudo, parece focalizar os eventos ambientais envolvidos para atingir um objetivo ou resolver uma tarefa e não o comportamento ou a estra- 
tégia comportamental do parceiro (Hamann et al., 2011; Tomasello, 2003, 2009, 2011)

As crianças, concebidas como agentes de criação e transmissão de cultura, desde os primeiros anos, dispõem de um repertório comunicativo e de habilidades que lhes proporcionam ampliar e especificar um processo de significação em curso. Essas habilidades podem ser inferidas de emoções, movimentos, gestos, vocalizações etc., ao compartilharem algo com os parceiros; no caso específico deste estudo, com os coetâneos.

Exemplos podem ser encontrados nos estudos empreendidos por Amorim (2012), Amorim, Anjos e Rossetti-Ferreira (2012), Carvalho, Império-Hamburger e Pedrosa (1998), Carvalho e Pedrosa (2002), Corsaro (2011), Corsaro (1997/2011), Delvan e Cunha (2010), Lucena (2010), Pedrosa e Eckerman (2000), que observaram a construção de brincadeiras de crianças pequenas e inferiram processos de significação, mesmo quando as crianças ainda apresentavam um sistema de representação não integralmente elaborado. Elas apreendiam e expressavam significações utilizando certas habilidades corpóreas que lhes permitiam significar e por vezes construir suas culturas de pares no grupo de brinquedo.

Corsaro (1997/2011) define cultura de pares (peer culture), como um "conjunto estável de atividades ou rotinas [itálico nosso], artefatos, valores e preocupações que as crianças produzem e compartilham em interação com as demais" (p. 128). Essa cultura de pares pode ser originada no mundo adulto ou criada e transformada no próprio grupo de interação de crianças que se encontram com frequência e se reconhecem pertencentes àquele grupo - o grupo de brinquedo.

Corsaro $(2011,1997 / 2011)$ evidencia duas características fundamentais na consolidação da cultura de pares: estabilidade (estrutura de participação reconhecível) e transformação (embelezamentos). Tais transformações parecem cruciais para a manutenção do interesse das crianças na atividade, tornando esta mais atrativa e desafiadora, e, ao mesmo tempo, viabilizando sua continuidade por ainda persistir uma base reconhecível e estável.

É na direção dessas reflexões que este trabalho investiga a construção de rotinas compartilhadas que integram a cultura de pares de um grupo de brinquedo de crianças de dois anos, buscando evidenciar as duas características fundamentais de sua consolidação: estabilidade (estrutura de participação reconhecível) e transformação (embelezamentos). Experiências compartilhadas instigam a inovação, porque implicam processos de significação, instando cada participante a contribuir na elaboração do empreendimento lúdico.

\section{Método}

\section{Participantes}

Participaram da pesquisa 20 crianças de dois anos de idade, 11 meninos e nove meninas, que frequentavam o Grupo I de um Centro Municipal de Educação Infantil
(CMEI), da cidade do Recife, que atende famílias de camada de renda média e baixa. Todos os pais assinaram o Termo de Consentimento Livre e Esclarecido (TCLE), com permissão para participação de seus filhos com divulgação de imagens para fins de formação de docentes e divulgação científica. As autorizações exigidas pelo Comitê de Ética em Pesquisa foram anexadas ao protocolo e este foi aprovado.

\section{Procedimento de Coleta}

O grupo de crianças investigado foi videogravado duas vezes por semana, durante um período de quarenta e cinco dias, perfazendo um total de 11 sessões de observação com duração média de 24 minutos. As gravações foram feitas em situação de brincadeira livre, com a presença das educadoras e auxiliares. Tal procedimento foi realizado tendo em vista a valorização de suas rotinas e buscando evitar possíveis estranhamentos e reações negativas das crianças se levadas para um lugar não habitual, o que poderia causar constrangimentos por terem apenas dois anos e, assim, prejudicar o trabalho investigativo. A situação cotidiana com parceiros de idade escolhida para observação propiciaria, segundo a literatura especializada, a construção de rotinas de pares (cf., por exemplo, Carvalho \& Pedrosa, 2002; Corsaro, 1997/2011; Lucena, 2010; Pedrosa \& Eckerman, 2000).

As educadoras, apesar de presentes, não propunham atividades específicas, mas deixavam os objetos do próprio CMEI (brinquedos, colchonetes etc.) à disposição das crianças para manuseio. Entretanto, intervinham sempre que necessário para confortar alguma criança, eliminar riscos ou dirimir conflitos que surgissem.

\section{Procedimento de Análise}

A análise empreendida, essencialmente de cunho qualitativo, passou por diversas etapas, sendo a primeira delas a exposição das pesquisadoras ao material videogravado. As sessões foram observadas atentamente, repetidas vezes, a fim de serem identificados episódios interacionais que contemplassem os objetivos traçados para o presente estudo. Interessavam os segmentos videogravados que apresentassem a configuração de uma brincadeira instaurada no grupo, seguindo pistas como proximidade física e identificação de um tópico comum em que duas ou mais crianças estivessem envolvidas com trocas interativas conspícuas. Especial atenção era conferida aos episódios interacionais com potencial para persistir e se estender no grupo sem que isso fosse sugerido pelos adultos: admitia-se que a manipulação de objetos grandes ou ações que envolvessem deslocamentos no espaço seriam mais facilmente observadas por outras crianças e, portanto, esses comportamentos constituíam pistas para a escolha do segmento a ser analisado. Ações de fácil execução também teriam mais chance de ser realizadas por muitas crianças.

A transcrição e análise dos trechos selecionados foram norteadas por questões que aguçavam o olhar das pesquisadoras, como por exemplo: como as crianças 
orientam seus comportamentos para um objetivo comum? Elas fazem uma ação semelhante à do parceiro, ou seja, imitam os parceiros, ou realizam ações complementares às deles? Quais os desdobramentos desse comportamento no grupo? Que objetos são utilizados e de que forma as crianças fazem uso deles?

Foram utilizados diversos critérios para delimitar o início e o fim de um episódio. Os critérios escolhidos eram flexíveis e baseados no fluxo interacional em curso. O critério mais utilizado para determinar o início de um episódio foi a orientação da atenção das crianças (duas ou mais) para uma atividade comum. Para delimitar o fim do episódio, os critérios mais utilizados foram: a dispersão das crianças em relação à atividade da qual participavam e a mudança do tema da brincadeira.

Algumas brincadeiras se estendiam por toda ou quase toda a sessão, com intervalos no seu desenrolar. Nesses casos, foram feitos recortes internos aos episódios, dividindo-os em momentos para permitir que o leitor apreendesse melhor o que se desejava evidenciar.

\section{Resultados e Discussão}

O que se objetiva investigar, a construção de rotinas compartilhadas que integram a cultura de pares de um grupo de brinquedo, em crianças de dois anos, não corresponde, certamente, a uma grande quantidade de episódios de modo a que se possa adensar um extenso material examinado. Trata-se, ao contrário, de perscrutar fluxos interacionais que possibilitem explicitar desdobramentos de ações que propiciem às crianças examinadas alçarem e reconhecerem, em meio às suas ações e significações, uma produção coletiva: no caso da presente investigação, uma rotina lúdica, com potencial de orientar o grupo de brinquedo.

Como suporte empírico à discussão, foram escolhidos para análise dois episódios longos que descrevem a construção e os diferentes desdobramentos que se desenrolam em função do tema: arrastar. No primeiro, as crianças arrastam colchonetes e, em seguida, objetos sobre ele; posteriormente, uma criança se senta em um dos colchonetes e é deslocada pelos parceiros. No segundo, as crianças se revezavam para se sentar em um cesto e serem arrastadas pelos colegas.

No Episódio 1, intitulado Arrastando colchonetes, a brincadeira ganha forma a partir da interação de duas crianças - Ivy e Riel - que arrastam colchonetes, em roteiros vizinhos por toda a extensão de um pátio coberto. Esta ação se estende para algumas outras crianças presentes, que também se interessam em arrastar colchonetes. Aos poucos a rotina vai se transformando - ganha melhoramentos. Como a brincadeira é construída ao longo de toda a sessão, ela será discutida aqui em dois momentos; em cada um deles, as crianças dão novos contornos à brincadeira. Os atores da brincadeira serão indicados por nomes fictícios e notação, entre parênteses, de sexo/idade, em número de anos e meses.
Episódio 1: Arrastando colchonetes

Ivy $(\mathrm{F} / 2 ; 8)$, Riel $(\mathrm{M} / 1 ; 9)$, Daniel $(\mathrm{M} / 2 ; 2)$, Cássio $(\mathrm{M} / 2 ; 8)$, Cláudio $(\mathrm{M} / 1 ; 10)$, Rique $(\mathrm{M} / 2 ; 5)$, Cadu $(\mathrm{M} / 2 ; 5)$, Israel $(\mathrm{M} / 2)$, [Anne $(\mathrm{F} / 3 ; 5)$ - criança do Grupo II].

Momento 1

... Ivy e Riel estão arrastando, cada um, um colchonete por toda a extensão de um pátio coberto. Cássio se aproxima de Ivy. A câmera muda de foco, mas ao retornar vê-se que Cássio joga um brinquedo no colchonete da garota. Ivy e Riel arrastam seus colchonetes para o outro lado do pátio [onde estão as educadoras e outras crianças]. Cássio vê outro colchonete livre e o pega para arrastá-lo. Antes, coloca sobre ele um brinquedo de borracha e uma garrafa. Ele sai arrastando o colchonete e vê que a educadora segura um brinquedo; faz a volta e se aproxima dela. Ele pede o brinquedo que a educadora segurava: estende a mão em direção ao brinquedo e, depois, bate no seu colchonete [como se pedisse a ela para colocá-lo ali]. A educadora cede o brinquedo e Cássio o coloca sobre o colchonete. Cássio e Ivy abalroam os seus colchonetes e dão gargalhadas. Ivy segue Cássio, e Riel arrasta seu colchonete seguindo o de Ivy...

No fragmento apresentado, Cássio, ao se introduzir na brincadeira, basicamente repete a mesma ação iniciada por Riel e Ivy: arrastar o colchonete. Contudo, logo em seguida, o garoto adiciona um elemento novo ao modelo original da atividade: ele coloca garrafas pet e brinquedos em cima do colchonete para arrastá-lo, como já tinha feito antes, ao colocar objetos sobre o colchonete de Ivy. Pode-se dizer que o menino renova o próprio interesse em continuar brincando com um enredo que se repete.

Ao longo da descrição do episódio, é possível conferir que a repetição da ação de arrastar, de certa forma, garante a continuidade e fluência de uma rotina em construção. Ela permanece no grupo e se propaga, pois, aos poucos, instiga outras crianças, que reproduzem a mesma ação e potencializam sua consolidação no grupo (Corsaro, 2011, 1997/2011; Corsaro \& Johannesen, 2007).

Paralelamente a essa reflexão, pode-se discutir a caracterização da brincadeira enquanto cultura, alinhando-se argumentos que apontam repetição e até estereotipia em brincadeiras consideradas universais, mas acomodando aspectos circunscritos a diferentes agrupamentos culturais. Bichara, Lordelo, Carvalho e Otta (2009), ao discutirem a brincadeira enquanto prática cultural, sugerem que a brincadeira é um dos universais culturais identificados, por exemplo, pela Antropologia - tais como os rituais de casamento, de saudação, tabus alimentares etc. As autoras realçam que, mesmo apresentando caráter de universalidade, as práticas sociais engendram idiossincrasias de cada cultura. As análises das brincadeiras empreendidas por elas revelam uma tensão entre o que é universal (aquilo que se repete em todas as culturas) e a inovação/diversidade (aquilo que é específico - o que as torna distintas). 
Lucena, J. M. F. \& Pedrosa, M. I. (2014). Estabilidade e Transformação na Construção de Rotinas Compartilhadas no Grupo de Brinquedo.

Tensão similar também é observada nas brincadeiras analisadas na presente investigação. Observa-se repetição de certas ações que parecem ser uma característica necessária à inovação. Nas brincadeiras aqui investigadas também estão presentes os elementos centrais da constituição de uma prática cultural: repetição e inovação.

Outro ponto importante a ser destacado é a estrutura simples dessa brincadeira - arrastar um colchonete pela sala. Segundo Corsaro (1997/2011), é justamente essa simplicidade e a já comentada repetição que favorecem a extensão da rotina para outros pares. Cabe destacar que os melhoramentos que ocorrem são realizados muito ao acaso - uma ação acidental acontece e, no fluxo das interações, principalmente a depender da forma como este evento acidental foi recortado e acolhido pelo parceiro, ele pode ser incorporado como parte do enredo da brincadeira, tal como ilustrado na Figura 1.
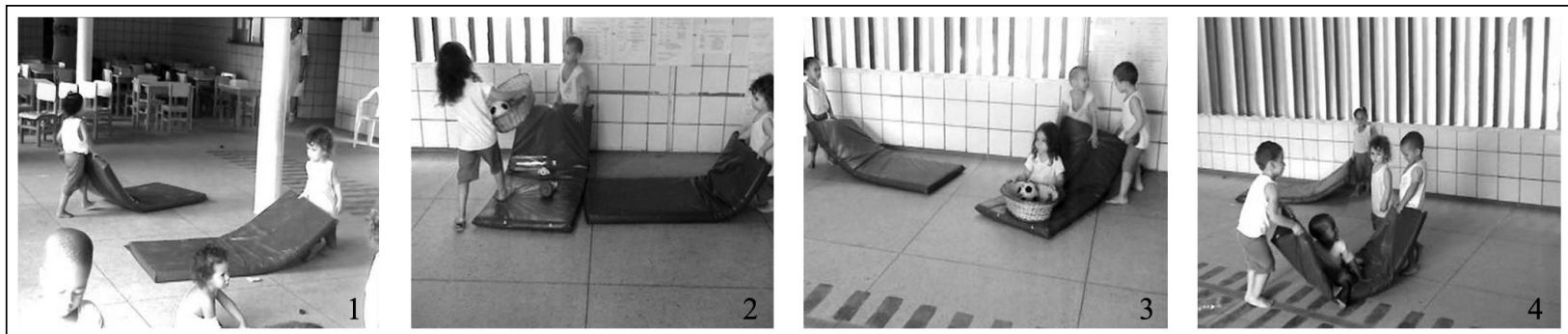

1. Ivy e Riel arrastam colchonetes; 2 . Anne põe o pé no colchonete impedindo que Cássio o arraste; 3 . Ela se senta no colchonete e Cássio e Cadu levantam-no tentando tirá-la de lá; 4. Cláudio ocupa o lugar de Anne, mas acha graça quando os meninos balançam o colchonete. A briga se transforma em brincadeira e o colchonete é arrastado com ele em cima.

Figura 1. Criando uma brincadeira.

\section{Momento 2}

... Anne, uma menina do Grupo II, coloca um pé no colchonete que Cássio arrasta, impedindo-o de continuar brincando. O garoto protesta e Anne se senta no colchonete segurando um cesto de vime com brinquedos. Cássio chora e faz algumas tentativas para tirar Anne de lá, experimentando posições diferentes de puxar o colchonete, mas ela não sai. Enquanto isso, Cláudio senta-se no colchonete que Riel arrasta e Cadu disputa o colchonete com Riel. Cláudio sai do colchonete e Cadu passa a puxá-lo com Riel, segurando na outra extremidade. Riel se senta no chão, segurando firmemente o colchonete, e consegue tirá-lo das mãos de Cadu. Em seguida, arrasta-o para o outro lado do pátio e retorna sem ele. Cadu se aproxima de Cássio, segurando com ele o colchonete onde Anne está sentada. Ivy se aproxima e assiste aos protestos de Cássio, que chora e tenta puxar o colchonete para Anne sair. A educadora se aproxima e conversa com a menina, tentando convencê-la a se levantar e brincar em outro local. Enquanto isso, Cássio segura com uma mão o colchonete e com a outra joga brinquedos sobre ele. O garoto choraminga e Anne finalmente sai do colchonete levando o cesto. Cláudio, então, se senta no colchonete e Cássio novamente protesta chorando. Cadu segura na outra ponta e começa a puxá-lo. Cláudio acha graça e dá um gritinho. Cássio, que já segurava na outra ponta do colchonete, também puxa. O efeito desta ação esboça, acidentalmente, o início de uma brincadeira de puxar o colchonete com uma criança sobre ele, sendo, portanto, arrastada pela sala. Os dois garotos caem ajoelhados espremendo
Cláudio, que, sorrindo, consegue se livrar daquele sufoco. Ivy observa toda a cena, segurando o seu colchonete e depois volta a arrastá-lo. Há um momento de tumulto entre as crianças e elas ainda passam cerca de cinco minutos envolvidas nessa atividade de arrastar o colchonete de um lado a outro do pátio. Elas disputam a posse dos colchonetes, revezam-se na ação de arrastá-los, colocam objetos e brinquedos em cima deles e o arrastam novamente. Outros parceiros se incorporam ao grupo. A brincadeira só termina quando a educadora pede para as crianças guardarem os colchonetes na sala.

Pode-se perceber que um novo incremento foi adicionado à ação principal de arrastar: uma criança fica sobre o colchonete e este é arrastado, agora como suporte que propicia o deslocamento de uma criança. Primeiramente, Cássio faz força para puxar o colchonete e tirar Anne que está sentada sobre ele. Como não consegue, ele chora e continua colocando garrafas plásticas em cima do colchonete. Quando finalmente a menina sai, é Cláudio que se senta nele. O garoto é menor e mais leve do que a colega, mas, mesmo assim, a força empreendida por Cássio não é suficiente para fazer com que Cláudio saia de lá. É quando Cadu também começa a puxar o colchonete com Cássio e ele se desloca com Cláudio sobre ele.

A ação de puxar o colchonete sobre o qual o colega está sentado produz um fato novo: as crianças observam que o colega pode ser deslocado junto com o colchonete, tanto quanto faziam com os brinquedos. Este efeito tonou-se divertido para as crianças envolvidas, pois sorriem, dão gargalhadas, vibram e, em seguida, estendem a ação de 
puxar o colchonete em diversas direções do pátio, incorporando esse embelezamento à estrutura de participação. Não se sabe que outros desdobramentos essa brincadeira ganharia, pois "arrastar o colchonete com o colega sobre ele" foi interrompido por um momento de tumulto entre as crianças.

Interessante é que esta ação de arrastar um colchonete com os aspectos que lhe foram acrescentados parece se estabelecer como uma brincadeira reconhecível para este grupo de crianças - uma rotina de pares. No Episódio 2 - Deslocando o colega no cesto -, observa-se a retomada dessa estrutura de participação, mas ao invés de a criança sentar-se sobre um colchonete e este ser arrastado, ela se senta em um cesto de vime, disponível no mesmo pátio, que é puxado por um grupo de colegas que seguram um elástico preso ao cesto. Outro grupo de crianças se ajusta em movimentos de empurrar o cesto para ajudar a deslocar o colega por toda extensão do pátio coberto.

Episódio 2: Deslocando o colega no cesto

Lia (F/2;1), Luana (F/2;4), Israel (M/2), Berto (M/2;2), Cássio $(\mathrm{M} / 2 ; 7)$, Cadu $(\mathrm{M} / 2 ; 5)$, Ana (F/2), Leny $(\mathrm{F} / 2)$, Deise $(\mathrm{F} / 2 ; 4)$, Daniel $(\mathrm{M} / 2 ; 1)$, Vitor $(\mathrm{M} / 2 ; 5)$, Cláudio $(\mathrm{M} / 1 ; 9)$, Liliane $(\mathrm{F} / 1 ; 11)$, Sandro $(\mathrm{M} / 1 ; 11)$.

Momento 1

Quando a sessão começa, Lia está sentada num cesto de vime com um elástico preso nele. Antes de Lia, outras cinco crianças experimentam entrar nesse cesto. A menina é puxada pelos seus colegas [a princípio: Luana, Israel, Berto, Cássio e Cadu]. Eles estão enfileirados ao longo do elástico que seguram e puxam Lia pelo pátio coberto. Ana se aproxima, se agacha e tenta empurrar o cesto por trás, mas parece não conseguir acompanhar o ritmo do grupo que puxa Lia. Deise olha para Ana e faz a mesma tentativa, mas também não acompanha o grupo. Ana faz mais duas tentativas até conseguir ajustar-se ao ritmo do grupo. Logo em seguida, as crianças que puxam o elástico param, pois esbarram em um colega - Cláudio, que estava sentado no chão. Leny e Daniel observam os parceiros. As crianças retomam a ação de puxar a colega, mas param, novamente, agora por causa de uma disputa entre Cássio e Cadu para pegar a ponta do elástico. A educadora se aproxima para mediar a negociação entre eles: conversa, coloca a mão de um e de outro em partes distintas do elástico e, em seguida, autoriza as crianças a continuarem a puxar Lia. Enquanto espera a negociação, Lia pega uma garrafinha plástica do chão mas joga fora em seguida. Daniel segura o elástico e Ana, erguida, coloca seu pé no cesto. Leny aproxima-se, olhando para o cesto. Ana sai e Leny assume o lugar de Ana para empurrar o cesto. Leny olha rapidamente para Ana e esta põe algo no cesto e passa a integrar o grupo dos que seguram no elástico para puxar Lia. As crianças continuam sua empreitada de puxar Lia, agora com a ajuda de Leny que ocupa novamente a posição de empurrar o cesto. Enquanto puxam, as crianças emitem um som ["an, an, an"] que parece ter sido iniciado por Cadu. O grupo para novamente por causa de nova disputa entre Cássio e Cadu para segurar a ponta do elástico. A educadora, mais uma vez, intervém. Cássio não acolhe bem a sugestão da educadora e tenta segurar o lado do elástico que ela reservou para Cadu. A educadora reafirma a divisão feita anteriormente e sai. Cássio tenta mais uma vez segurar a parte do elástico que Cadu segura. Fica a impressão de que Cássio busca um maior apoio para puxar Lia com mais força. A educadora intervém novamente pedindo para que Cássio não tire a mão de Cadu do elástico. O garoto sai. Berto olha para Cássio. Israel olha para Cássio e para a educadora. Logo em seguida, Ana tropeça em uns baldes e também sai da brincadeira. Leny se afasta. O grupo segue, agora com Cadu, Berto, Israel e Luana puxando Lia. Enquanto isso, Leny volta para o seu lugar de empurrar. Cássio também volta a puxar o cesto, assumindo agora o último lugar na fileira. A câmera muda de foco e quando retorna vê-se Deise assumindo a posição de empurrar. Liliane e Ana seguem o grupo, observando-o. O grupo alcança uma das extremidades do pátio, faz a volta e continua a puxar Lia ...

Pode-se supor que a estrutura de participação experimentada no episódio dos colchonetes, que aconteceu na semana anterior, tenha favorecido a "invenção" dessa brincadeira de deslocar o colega no cesto. Põe-se "invenção" entre aspas porque é como se esta nova brincadeira - deslocar o colega no cesto - fosse uma variação da brincadeira de arrastar o colchonete. Com base em quais evidências é possível se fazer essa suposição?

Uma primeira evidência que a sustenta está na semelhança encontrada entre as estruturas de participação dessas duas brincadeiras. Ambas parecem se desdobrar a partir de um tema comum: arrastar. Cabe lembrar que na brincadeira do colchonete, ora as crianças simplesmente arrastam o colchonete por toda a extensão do pátio, ora colocam objetos em cima deles e os arrastam, ora arrastam o colchonete com uma criança sobre ele. Já no Episódio 2, fica evidente que elas retomam a ação de arrastar um grande objeto, só que agora esse objeto é um cesto com uma criança dentro dele. Um segundo aspecto que aponta para a semelhança entre as brincadeiras é a adesão rápida das crianças no caso do segundo episódio, o do cesto. É interessante apontar que dois dos protagonistas desta brincadeira protagonizaram também a brincadeira de arrastar o colchonete (Cadu e Cássio), e todas as crianças do grupo a presenciaram. É como se elas reconhecessem esta forma de brincar, compartilhando com os parceiros significados que configuram um roteiro-base, representado pela ação de arrastar um grande objeto pelo chão, agora já incrementado por se tornar um suporte para carregar e deslocar outros objetos ou mesmo uma criança: uma rotina instaurada e prontamente reconhecida, que passou a pertencer ao grupo de brinquedo. 
É possível especular que a estrutura que regulou as ações das crianças nas duas brincadeiras seja um atrator, tal como definem Carvalho et al. (1998), desencadeado pelo processo mais específico de regulação, ou seja, a correlação. $\mathrm{O}$ atrator, que, no caso, poderia ser representado pela ação de arrastar, sintetiza a seleção convergente de ações em direção a um acordo de significados construídos na própria interação das crianças. Ele indica não somente a convergência; potencialmente, interfere na seleção de significados novos a serem compartilhados em torno do tema comum da brincadeira.

A presença de um atrator reduz e condensa as informações do campo interacional e ao mesmo tempo garante uma maior precisão. Esta redução elimina os ruídos que podem estar presentes na sequência interacional e realçam as semelhanças, dispensando "aquilo que não é relevante (não tem significado) para o acordo" (Carvalho et al., 1998, p. 168). No caso do exemplo aqui apresentado, a ação de arrastar pode ser compreendida como este significado condensado que informa aos interagentes do que e como brincar. Cria-se, assim, um significado compartilhado - arrastar - com potencial de persistir e fazer parte da cultura de pares dessas crianças, "no sentido de ser capaz de evocar episódios semelhantes em outros momentos da história do grupo" (p. 171).

Cabe comentar ainda que as diferenças que aparecem na brincadeira do cesto, quando esta é comparada à do colchonete, podem até ser dispensadas para a consolidação do acordo que permite à configuração coletiva ser reinstaurada em outros momentos da história do grupo. Contudo, estas diferenças não deixam de ser consideradas e podem ser compreendidas como um pano de fundo da nova brincadeira. $\mathrm{O}$ que se quer dizer é que, ao mesmo tempo que a brincadeira do cesto possui uma estrutura de participação similar à da brincadeira dos colchonetes, ela tem as suas peculiaridades que a distinguem, haja vista serem tomadas como duas brincadeiras distintas, mesmo que se desdobrem a partir de um tema comum: arrastar.

Dentre estas peculiaridades estão as especificidades das pequenas regulações estabelecidas entre as crianças. Em cada uma das brincadeiras é possível perceber que existem certos tipos de acordos que só fazem sentido para aquele momento de interação com aqueles interagentes. Muitas dessas influências são sutis e realizadas, preponderantemente, por meio de recursos não verbais. Podem-se tomar como exemplos os primeiros revezamentos realizados pelas meninas que empurram o cesto - Ana e Deise. Esses revezamentos são orientados exclusivamente por olhares e postura do corpo - voltando-se/inclinando-se para o cesto ou em outra direção. Ou seja, essas ações comunicam ao parceiro a intenção de empurrar o cesto, a marcação de quem é o turno de empurrar etc. A criança se antecipa ou se esquiva para empurrar o cesto em função dos sinais que os movimentos realizados pelo parceiro lhe oferecem.

Outros movimentos específicos, como posicionar o pé em cima do cesto, ou ainda, a permanência da ação de empurrar o cesto também comunicam ao parceiro se é ou não a sua vez de empurrar. Isso pode ser evidenciado durante o segundo revezamento realizado, entre Ana e Leny. No momento em que o grupo para de puxar o elástico, Ana também para de empurrar, colocando um de seus pés na borda do cesto. Leny, que estava perto da colega, se aproxima olhando para o cesto. Ana troca olhares com a colega e permanece com o pé em cima do cesto, mas em seguida se afasta. Leny, prontamente, assume o lugar de Ana para empurrar o cesto e olha para a colega.

É neste sentido que se pode dizer que os ajustamentos de ações entre as meninas se constituem como códigos comunicativos que podem ser alçados do campo interacional constituído pelas crianças. Reforça-se a ideia de que esses códigos surgem em um contexto interacional específico em que a capacidade exclusivamente humana de sintonizar-se com o parceiro merece lugar de destaque e possibilita que a comunicação se efetive (Bruner, 1983, 1990/2011; Eckerman \& Peterman, 2001; Pedrosa \& Carvalho, 2006; Tomasello, 2003, 2011; Wallon, 1934/1971).

Acompanhando o episódio, observa-se que a brincadeira ainda se desdobra mais uma vez no grupo - novos contornos lhe são adicionados - como ilustrado na Figura 2.
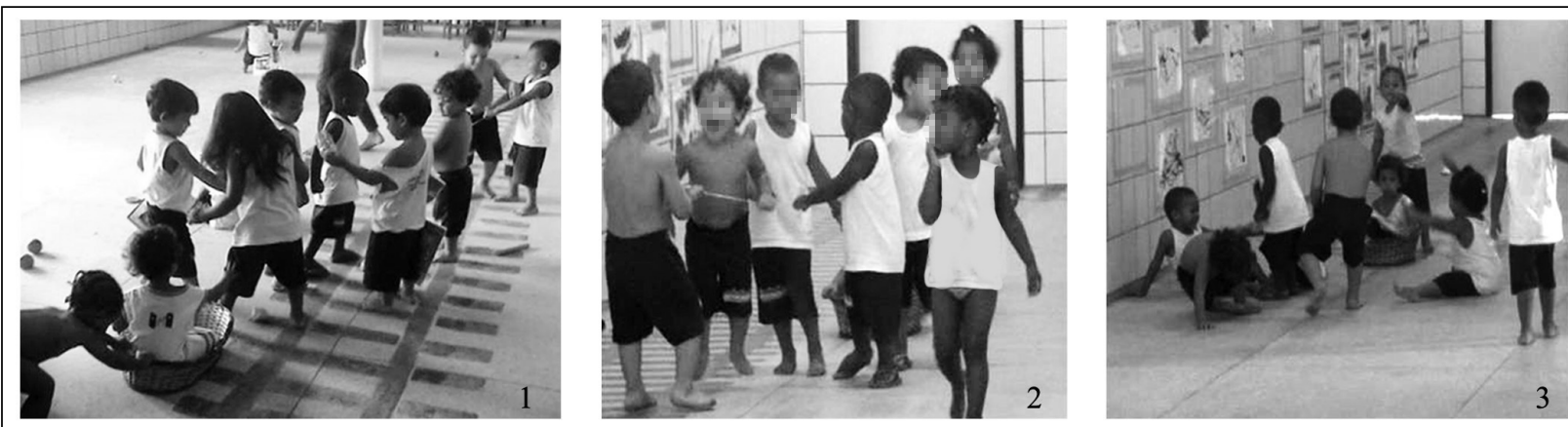

1. Lia, sentada no cesto, é puxada e empurrada pelos colegas; 2. Estes disputam o melhor lugar ao longo do elástico; 3. Novo incremento é feito à brincadeira; as crianças cantam e caem sentadas.

Figura 2. A brincadeira de arrastar com inovações. 


\begin{abstract}
Momento 2
... Berto começa a pular emitindo um som ritmado e melódico-um canto - ["tai, tai. tai, tai"], tropeça e cai no chão. As crianças sorriem olhando para o colega. Liliane segura o elástico. Berto se levanta, sorrindo, e pula novamente, emitindo o mesmo som. Faz uma breve pausa e Luana, então, começa a pular - chama a atenção a expressão de satisfação da menina, que fica o tempo todo com um sorriso no rosto. Berto volta a pular, cantar e cai no chão - agora o cair parece ser proposital. Cássio e Cadu também pulam e caem sorrindo. Luana se agacha um pouco, cantando "tai, tai", olhando para Cássio e cai sentada no chão. Liliane se afasta um pouco do grupo, dá um gritinho e cai no chão, deitando-se de braços abertos. A maior parte das crianças está novamente de pé e Deise tenta empurrar o cesto mais uma vez. Ela olha na direção de Cadu, aponta para frente indicando para o menino o elástico e diz: "Puxa ai ó." Vitor se aproxima, dá uns pulinhos discretos, cantando o "tai, tai" e se afasta...
\end{abstract}

O exemplo mostra que uma ação acidental é selecionada e recortada para fazer parte do roteiro da brincadeira em construção. Mas como é possível fazer essa inferência do trecho apresentado? Que evidências sustentam essa afirmação?

O desenrolar da sequência interativa não deixa dúvidas de que a primeira queda de Berto, ao pular e cantar o "tai, tai”, foi acidental. Ele tropeçou em suas próprias pernas ao pular e caiu. Cadu, Luana e Cássio olham para ele e acham a cena engraçada. Pelo desdobramento da sequência interativa infere-se que o sorriso dos parceiros transforma o acidente em algo interessante e potencializa o recorte de uma nova ação a ser incorporada ao script da brincadeira, instigando sua repetição por todos.

Essa suposição é confirmada, na medida em que Luana passa a imitar os pulos e canto iniciados por Berto e, depois, o próprio Berto pula, canta e cai, sendo que esta segunda queda não mais parece ser acidental, pois ele não tropeça e cai sorrindo, orientado para os parceiros. Esta suposição é confirmada, quando Cadu e Cássio pulam e caem no chão, sorrindo e cantando o "tai, tai" - última foto da Figura 2.

Corsaro (2011, 1997/2011), bem como Pedrosa e Eckerman (2000) discutem que as ações das crianças, quando envolvidas em rotinas de pares, são transformadas com a repetição, ganhando novos contornos. $\mathrm{Ou}$ seja, à estrutura de participação, as crianças agregam novos elementos, e a brincadeira se complexifica. No caso do exemplo discutido: arrastar foi complexificado com a função de servir de suporte; coordenado ao puxar e empurrar; e a sequência recebeu embelezamento com o pular, cantar e cair.

A continuidade e fluência de uma estrutura de participação simples e repetitiva possibilitam que a rotina da brincadeira se estabeleça no grupo e envolva as crianças presentes em uma construção coletiva, em que todas participam, mesmo que seja de diferentes formas e em diferentes níveis ou momentos. Vê-se que a brincadeira de arrastar o cesto com o colega dentro permanece e se difunde entre as crianças do grupo. Mesmo as mais novas, que não têm a habilidade motora refinada para se ajustar às ações e ritmo dos parceiros, acompanham a construção da rotina e participam dos diferentes formatos dados a ela da maneira que lhes é possível. Tome-se como exemplo o de Liliane, que mesmo desajeitadamente e sem acompanhar o ritmo da vocalização "tai, tai", realizada pelos colegas, repete a ação iniciada por Berto de pular, cantar e cair, a seu modo: ela levanta os braços, dá um gritinho e cai no chão, deitando-se de braços abertos. Essa é a forma de Liliane participar da brincadeira e revelar que compartilha os novos embelezamentos que estão sendo adicionados à rotina do arrastar.

\section{Momento 3 \\ ... Em um dado momento, Lia sai do cesto e Cássio, uma criança mais pesada, entra e senta. Deise conti- nua tentando empurrar o cesto e Cadu, Luana, Israel e Berto tentam puxá-lo. Cláudio adere ao grupo dos puxadores. Liliane coloca uma de suas pernas na frente do cesto em um espaço em meio ao elástico. As crianças sentem dificuldade de puxar, possivelmente pelo maior peso do garoto e, talvez, porque Liliane está na frente, dificultando seu deslizamento. A educadora, então, a tira de lá. Deise continua tentando empurrar o cesto, mas o grupo que puxa o elástico procura melhor se organizar para puxá-lo. A menina faz uma expressão de exaustão pela força empreendida e se afasta um pouco do cesto. As crianças conseguem puxar o cesto alguns centímetros e Cadu - criança que parece fazer mais esforço no puxar - vibra, agitando os braços no ar.}

Nesse trecho descrito fica evidente o esforço empreendido pelas crianças para se ajustarem umas às outras na tarefa de deslocar o cesto com o colega dentro. Contudo, mesmo demandando bastante força física das crianças, elas parecem empenhadas na tarefa. E é por meio de suas ações que as crianças revelam o engajamento na brincadeira em construção. Revelam também que compartilham entre si significados que lhes permitem coordenar as ações em uma construção cooperativa de uma brincadeira nova para o grupo, brincadeira esta que persiste com um tema-base arrastar-, o qual, ao mesmo tempo que garante momentos reconhecíveis de estabilidade, possibilita a transformação, a inclusão da novidade na brincadeira.

\section{Considerações Finais}

Pode até parecer contraditório o argumento aqui defendido que apresenta o binômio estabilidade-transformação como a base do processo de construção e persistência da cultura de pares. Contudo, esta forma de conceber o fenômeno faz parte de um raciocínio dialético, não-linear, que dá suporte à formulação da perspectiva sociointeracionista, compartilhada pela psicoetologia, que guia os 
estudos sobre desenvolvimento humano e que inspiraram essa reflexão. A base do argumento que sustenta a compreensão que se tem do processo de construção de conhecimentos culturais como, por exemplo, a cultura de pares, é que "significados persistentes, configurações estáveis, estereotipias, rituais são momentos necessários da dinâmica dos campos interacionais, como os degraus de uma escada, a partir dos quais pode emergir outra vez a novidade" (Carvalho et al., 1998, p. 173).

Ademais, os trechos analisados nos dois episódios discutidos revelaram que momentos de estabilidade e de transformações integram a atividade de arrastar. O envolvimento das crianças nesse tipo de brincadeira oferece evidências sobre suas competências de atribuir significados à atividade que experienciam, de construir ativamente novos significados e de introduzir transformações nesses significados construídos. Isto acontece pela ação, mesmo antes que a criança possa usar a linguagem verbal de uma forma mais efetiva.

A investigação detalhada de processos culturais na primeira infância indica a necessidade e a pertinência de se explicitar a ontogênese humana, refletindo sobre a constituição desse processo para compreender os ambientes favoráveis ao modo de vida sociocultural que possibilitou, e que certamente continua possibilitando, o desenrolar de nossa história evolutiva. Nessa direção, novas investigações podem contribuir com reflexões como estas aqui empreendidas, uma vez que análises qualitativas são apropriadas para perscrutar processos de transformações inerentes ao estudo do desenvolvimento, mas apresentam limitações em face da abrangência do material analisado. Segundo Minayo (2012) outras fontes de informação são relevantes para assegurar a fidedignidade das interpretações, e necessário se faz atentar para fatos que possam contradizer as hipóteses interpretativas já realizadas.

\section{Referências}

Amorim, K. S. (2012). Processos de significação no primeiro ano de vida. Psicologia: Teoria e Pesquisa, 28(1), 45-53.

Amorim, K. S., Anjos, A. M., \& Rossetti-Ferreira, M. C. (2012). Processos interativos de bebês em creche. Psicologia: Reflexão e Crítica, 25(2), 378-389.

Bichara, I. D., Lordelo, E. da R., Carvalho, A. M. A., \& Otta, E. (2009). Brincar ou brincar: Eis a questão. A perspectiva evolucionista sobre a brincadeira. In E. Otta \& M. E. Yamamoto (Eds.), Psicologia evolucionista. (pp. 104-113). Rio de Janeiro, RJ: Guanabara Koogan.

Bruner, J. (1983). Child's talk: Learning to use language. New York: W. W. Norton.

Bruner, J. (2011). Actos de significados. Lisboa, Portugal: Edições 70. (Original publicado em 1990)

Carvalho, A. M. A., Império-Hamburger, A., \& Pedrosa, M. I. (1998). Interaction, regulation, and correlation in the context of human development: Conceptual discussion and empirical examples. In M. Lyra \& J. Valsiner (Eds.), Construction of psychological processes in interpersonal communication (pp. 155-180). Stamford, CT: Ablex.
Carvalho, A. M. A., \& Pedrosa, M. I. (2002). Cultura no grupo de brinquedo. Estudos de Psicologia (Natal), 7(1), 181-188.

Corsaro, W. A. (2011). Peer cultures. In J. Qvortrup, W. A. Corsaro, \& M. Honig (Eds.), Handbook of childhood studies $\left(2^{\text {nd }}\right.$ Rev. ed., pp. 301-315). Basingstoke, UK: Palgrave.

Corsaro, W. A. (2011). The sociology of childhood ( $3^{\text {rd }}$ ed.). Thousand Oaks, CA: Pine Forge Press. (Original work published 1997)

Corsaro, W. A., \& Johannesen, B. O. (2007). The creation of new cultures in peer interaction. In J. Valsiner \& A. Rosa (Eds.), The Cambridge handbook of socio-cultural psychology (pp. 444-459). New York: Cambridge University Press.

Delvan, J. da S., \& Cunha, P. M. (2010). A criação de uma cultura de grupo na brincadeira: Um estudo com crianças entre 2 e 4 anos. Interação em Psicologia, 14(1), 53-60.

Eckerman, C. O., \& Peterman, K. (2001). Peers and infant social/ communicative development. In G. Bremner \& A. Fogel (Eds.), Blackwell handbook of infant development (pp. 326350). Oxford, UK: Blackwell.

Hamann, K., Warneken, F., Greenberg, J., \& Tomasello, M. (2011). Collaboration encourages equal sharing in children but not chimpanzees. Nature, 476, 328-331.

Lucena, J. M. F. (2010). Examinando os processos de assimilação, transformação, construção e compartilhamento de cultura entre crianças de dois anos no ambiente de creche (Dissertação de mestrado, Universidade Federal de Pernambuco, Recife, PE, Brasil).

Minayo, M. C. S. (2012). Análise qualitativa: Teoria, passos e fidedignidade. Ciência \& Saúde Coletiva, 17(3), 621-626.

Moll, H., Carpenter, M., \& Tomasello, M. (2010). Social engagement leads 2-year-olds to overestimate others' knowledge. Infancy, 1-18.

Pedrosa, M. I., \& Carvalho, A. M. A. (2006). Construction of communication during young children's play. Revista de Etologia, 8(1), 1-11.

Pedrosa, M. I., \& Eckerman, C. (2000). Sharing means: How infants construct joint action from movement, space and objects. In International Society for the Study of Behavioral Development (Ed.), Abstracts of the XVI ${ }^{\text {th }}$ Biennial Meetings of ISSBD (p. 438). Beijing, China: International Society for the Study of Behavioural Development.

Tomasello, M. (2003). Origens culturais da aquisição do conhecimento humano. São Paulo, SP: Martins Fontes.

Tomasello, M. (2009). Why we cooperate. Cambridge, MA: Massachusetts Institute of Technology Press.

Tomasello, M. (2011). Human culture in evolutionary perspective. In M. Gelfand (Ed.), Advances in culture and psychology (pp. 5-51). Oxford, UK: Oxford University Press.

Wallon, H. (1971). As origens do caráter na criança: Os prelúdios do sentimento de personalidade. São Paulo, SP: Difusão Européia do Livro. (Original publicado em 1934) 